\title{
Synoptic patterns associated with landslide events in the Serra do Mar, Brazil
}

\author{
Marcelo E. Seluchi and Sin Chan Chou \\ National Institute for Space Research (Instituto Nacional de Pesquisas Espaciais - \\ INPE), Cachoeira Paulista, SP, 12630-000, Brazil \\ $+55-12-31868400$ \\ $+55-12-31012835$ \\ seluchi@,cptec.inpe.br, chou@cptec.inpe.br
}

\begin{abstract}
Heavy rains frequently occur over the Serra do Mar, southeast coastal mountain region in Brazil, and cause landslides and life losses especially during summer season. The objective of this work is to produce a synoptic climatology of heavy rainfall episodes of the period from November to April using ten-year re-analyses data. The identification of the synoptic pattern of these events should provide guidance to the forecasters. The landslides events were mostly related to the South Atlantic Convergence Zone (SACZ) and cold front passages. These systems differed from climatology by exhibiting more intense characteristics for the frontal situations and a blocking circulation configuration for the SACZ situations. In both cases, the composite fields showed the $250-\mathrm{hPa}$ mass divergence was strikingly more intense than climatology and had a preferred location to be positioned in the 24 hours before the landslide events. Anomalies of this ten-year event climatology showed above normal moisture anomalies, which are more evident in the SACZ cases.
\end{abstract}

Keywords: Heavy rains, South Atlantic Convergence Zone, South America Abbreviations: SACZ: South Atlantic Convergence Zone; NCEP: National Centers for Environmental Prediction;

\section{Introduction}

The Serra do Mar is a mountain chain that runs near the southeastern coast of Brazil with some of its peaks exceeding 1,000 meters (See Figure 1). Only a few portions of the original forest, the so-called Mata Atlântica, can be found preserved in the Serra do Mar. The region is frequently affected by heavy rainfall, floods and landslides, which eventually cause property destruction, road traffic disruptions and deaths, especially during summer. The combination of high 
moisture content in the lower layers of the atmosphere, which is typical in this coastal region, with warm summer air and forced ascent by the mountains creates the thermodynamically unstable conditions almost every day. Moreover, the region is on the way of transient perturbations and other large scale systems that may enhance the air ascent. The interaction between the large scale perturbations and the local convective instability may generate heavy persistent precipitation and result in landslides of various portions of Serra do Mar.

Some articles have related the influence of topography on the different weather systems, from mountain waves (Durran, 1990) to planetary waves (Satyamurty et al, 1980). A number of numerical simulations have been carried out to understand the mechanisms that determine the heavy rainfall events in the mountain regions, such as those performed by Romero et al (2000) in Spain, Ducrocq et al (2002) in France. Some works studied the role of soil and vegetation (Romero et al., 1995), or model horizontal resolutions (Gallus, 1999) on the quality of the forecasts and simulations were also performed. Over Brazil, a few modeling studies were undertaken. Haas (2002) related the heavy orographic precipitation with the extratropical cyclogenesis in south of Brazil. Rozante (2001) evaluated Eta Model simulations, adopting different horizontal and vertical resolutions concluding that the increase of both horizontal and vertical resolutions favored to improve the quality of the simulations of a frontal passage. Mendes (2006) simulated a heavy rain event in the Serra do Mar, the 3-km, non-hydrostatic version of the Eta Model favored the simulations to approach the observed precipitation amount.

Despite the great damage caused by the landslides around the Serra do Mar, little work has been produced for this special region. An example is the article carried out by Satyamurty et al. (2002) which describes a case of South Atlantic Convergence Zone (SACZ) which caused floods, generalized landslides, road block between the two major cities, Rio de Janeiro and Sao Paulo.

The objective of this work is to study and identify the synoptic pattern associated with landslide events over the Serra do Mar to be used as guidance for the operational forecasters. The pattern will be identified by means of a synoptic climatology of these events. 


\section{Data and Methodology}

The National Centers for Environmental Prediction (NCEP) re-analyses data (Kalnay et al., 1996) were used for characterizing the synoptic patterns associated with landslide events in the Serra do Mar region in the period from 1995 to 2005. This dataset has regular horizontal resolution of 2.5 degrees x 2.5 degrees latitudelongitude. The dates of these events were taken from a database created by the Technology Research Institute of Sao Paulo (Instituto de Pesquisas Tecnológicas) and they are limited to the casualty cases which occurred in the Serra do Mar region in Sao Paulo State. As most of the cases occurred during summer, the study period was taken between November and April.

The total of 39 cases between November 1995 and December 2005 were identified for this study. However, because the focus of this work is on large scale synoptic control aspects, heavy rain events resulting from isolated convective forcing were discarded, which represented around $15 \%$ of the events (6 cases).

Composite maps were constructed for 3-day event leading time and for 2-day event lagging time of the selected cases.

The SACZ events that are associated with landslides in the Serra do Mar are compared against the SACZ climatology constructed by Sanches (2002) using NCEP reanalysis data. Climatology for the frontal passages that reach the coast of the Sao Paulo State was also constructed employing NCEP reanalysis data. The frontal identification was provided by the Climanálise Journal edited by the Brazilian Institute for Space Research (Instituto Nacional de Pesquisas Espaciais, INPE) from 1986.

\section{Results}

The results are initially shown for the composite fields constructed from the major landslide events. Anomalies fields will show how these events depart from the mean conditions. The typical synoptic evolution is identified.

Table I lists the monthly total number of landslide events between 1995 and 2005. It shows that most of the events, about $61 \%$, occurred in January and February. The annual total maximum number of events occurred in 1999 and 2000 (6 episodes) and the minimum occurred in 1998 and 2001 (one episode). 


\subsection{Mean fields}

Figure 2.a depicts the mean sea level pressure averaged over the 33 cases associated with landslides in the Serra do Mar. As expected, this mean field shows a trough in the NW-SE direction, with axis crossing the state of Sao Paulo and extending toward the Atlantic Ocean. In this figure, a broad low pressure center, the Chaco Low, stands out over western Brazil and Paraguay and the Subtropical Anticyclone over the Atlantic Ocean appears displaced to the south of its climatological location (Seluchi and Marengo, 2000). The mean air temperature within the mid and lower troposphere, which is proportional to the $500 / 1000-\mathrm{hPa}$ layer thickness, exhibits a warm tongue (thickness ridge) near the coast at $22^{\circ} \mathrm{S}$ and a relatively colder center (thickness trough) inland to the south. However, the general pattern indicates that the lower level trough is embedded in a rather barotropic environment. Warm air advection prevails over the Atlantic coast and is more intense to the south of $35^{\circ} \mathrm{S}$.

The $850-\mathrm{hPa}$ mean specific humidity field (Figure $2 \mathrm{~b}$ ) shows maximum values centered over the trough, which is identified by the cyclonic (clockwise) turn of the wind over the southern and central part of the continent. Despite the transport of moisture from the Amazon region to the subtropical latitudes, the low level jet does not appear, at least on average, as a significant feature in landslide events in the Serra do Mar. The high values of specific humidity in the Bolivian Highplains should not be considered as they are inside the mountains.

The 500-hPa mean winds (not shown) exhibit closed anticyclonic circulation over the subtropical Atlantic Ocean that extends as a ridge toward midlatitudes and a short-wave trough to the north of the anticyclone. Thus the leading part of the trough is positioned over São Paulo coast.

At 250-hPa level (Fig 2.c) the winds exhibit the Bolivian High (Lenters and Cook, 1997) and the "Northwestern Cyclonic Vortex" (Kousky and Gan, 1981) which are typical summer features (Vera et al, 2006). A strong anticyclonic curvature flow positioned over the Serra do Mar is associated with mass divergence which extends toward the southwest above the surface trough.

A closer inspection revealed that among the 33 selected cases, 15 were associated with SACZ and 18 were related to frontal systems. These two weather systems are 
linked with troughs over central and eastern Brazil and will be studied separately. The mean surface maps produced for both systems are similar but show stronger low pressure center and lower 850 -hPa specific humidity values for the frontal cases that reach the coast of Sao Paulo. In the case of SACZ, the 500-hPa geopotential height trough exhibits shorter wavelength. On the other hand, the meridional temperature gradient at this level is stronger in the frontal case, which indicates stronger baroclinicity, as expected. The $250-\mathrm{hPa}$ mass divergence maximum is stronger for the SACZ case and positioned directly over the coast of Sao Paulo.

\subsection{Anomalies}

Composite of atmospheric fields are useful to describe the main atmospheric patterns that results in landslide events over Serra do Mar. However, the above results show the mean atmospheric state associated with two weather systems which are frequent during the summer season over South America. Thus, the determination of the distinguishable features from the normal conditions can help improve the forecast of these events. To this purpose, anomalies with respect to NCEP climatology were obtained. The climatology was taken for the period between 1950 and 1998 .

Figure 3 shows the mean sea level pressure and 500/1000-hPa layer thickness anomaly fields for SACZ and cold front cases. It is interesting to note some similarities in the mean sea level pressure anomaly field pattern for both events, as the positive anomalies over the Atlantic Ocean and the negative anomalies over the Southeast Brazil region that indicate more intense ridges and troughs than the NCEP re-analyses climatology. On the other hand, the negative anomalies over the Pacific Ocean are more evident in the SACZ case. The 500/1000-hPa layer thickness anomalies show that the air in the lower and mid troposphere is warmer for both frontal and SACZ events, with maximum anomalies over the trough. Important differences in 500/1000-hPa thickness can be noticed over Atlantic Ocean where the anomalies have opposite signs. The above-normal temperatures (Fig. 3a) in high pressure center suggest the relation between the SACZ events and atmospheric blocking system. In contrast, Figure $3 \mathrm{~b}$ shows a typical cold front signature with strong horizontal pressure gradient over the ocean, ahead of 
positive pressure anomalies. The cold air anomalies indicate the presence of a post-frontal anticyclone that merges with the subtropical anticyclone, similar to the pattern described by Dallavalle and Bosart (1975) for Northern Hemisphere. The 850-hPa wind and specific humidity anomalies (Fig.4) show that the maximum of humidity associated with the surface trough has above-normal values, over $1.5 \mathrm{~g} / \mathrm{kg}$, which are more evident in the SACZ case (Fig 4a). The winds at this level produce a maximum of cyclonic circulation anomaly extending from Sao Paulo toward the Amazon area for the SACZ case (Fig 4a), and to the southeast of the Sao Paulo coast for the frontal cases (Fig4b). These cyclonic circulation anomalies coincide with higher moisture anomalies.

The 500-hPa geopotential height and temperature fields exhibit strongest anomalies in high latitudes (Fig.5). The geopotential anomalies show a longwave pattern with a barotropic structure (Fig.5a) for the SACZ cases which is consistent with a blocking system. Moreover, over the coast of Sao Paulo State, a relative maximum of cyclonic vorticity advection and short temperature waves are present. This configuration confirms that the landslides occur in the moment the SACZ interact with shorter baroclinic waves. In Figure 5b, for frontal cases, a shortwave can be noticed in both temperature and geopotential height anomalies. It is worth noticing that in both cases the temperatures in the Serra do Mar region are marginally above normal. In addition, the absence of significant temperature anomalies at $925 \mathrm{hPa}$ and low instability indices reveal that these events do not contain above normal thermodynamic instability.

Figure 6 exhibits the $250 \mathrm{hPa}$ mass divergence and wind anomalies. These anomalies are clear along the coast of São Paulo state and reveal to be important features to the forecast of both events. Although to the south of this region, a wide band of convergence anomalies is present (Fig 6a and 6b), the associated circulation shows some significant differences. In the SACZ case, there is a cyclonic anomaly located around $23^{\circ} \mathrm{S}$ and $55^{\circ} \mathrm{W}$ which provides cyclonic vorticity advection in most part of the target region. The interaction of SACZ with short wave perturbations enhances the vertical motions and, consequently, the rain production. Farther south, the barotropic structure typical of blocking system is positioned over the Atlantic Ocean. In the frontal case, it is possible to identify the shortwave pattern with baroclinic characteristics. The $850-\mathrm{hPa}$ height wave, whose horizontal axis is oriented in the SW-NE direction, leads the upper level 
wave (positioned to the east). This westward tilt of the wave structure indicates the baroclinic character of these cases.

\subsection{Temporal evolution}

The above study has the purpose to identify the synoptic patterns associated with the landslides events in the Serra do Mar. In this section, the large scale conditions a few days prior to the landslides events are characterized in order to improve the confidence and the lead time of these forecasts.

Figure 7 shows the mean sea level pressure and 500/1000-hPa layer thickness mean anomalies for the SACZ cases and the cold front situations from the DAY-3 until DAY-1. In both cases, the features of the studied systems can be identified 72 hours before their occurrence. In the SACZ case, there are again clear evidences of a blocking system positioned over the Atlantic Ocean, associated with long pressure wavelengths at high latitudes and the presence of low pressure centers in the target region. The slow evolution of the synoptic conditions is consistent with the quasi-stationary character of the SACZ and the blocking systems. The presence of the SACZ over Serra do Mar for at least three days (upper panels in Fig. 7) cause the persistence of the rains and the increase of the accumulated amounts. The passage of cold fronts related to landslides can be detected, on average, with at least 72-hour lead time based on the propagation of the baroclinic wave (lower panels in Fig. 7). The $850-\mathrm{hPa}$ specific humidity and the 500-hPa geopotential height anomalies (not shown) reveal the propagation of perturbations associated with the cold fronts and the slow intensification patterns related to SACZ.

Figure 8 shows the $250-\mathrm{hPa}$ wind and mass divergence anomalies at different lead-times of the events. In the SACZ case, although the surface, 850-hPa and $500-\mathrm{hPa}$ fields show quasi-stationary conditions and a slow increase in the magnitude of the anomalies, the $250-\mathrm{hPa}$ winds seem to have more potential for prognosis. Initially, despite the slow evolution of the general patterns, one can detect a northeastward movement of the cyclonic circulation anomaly, though slow. On the other hand, the mass divergence, associated with the eastern half of the 250-hPa trough, attains its maximum magnitude and reaches the relevant region in between the DAY-1 or DAY-0. In the case of the frontal systems, it is also possible to notice that the $250-\mathrm{hPa}$ trough achieves its maximum intensity 
and reaches the region near the coast of Sao Paulo state within the 24 hours prior to the landslides.

\subsection{Precipitation}

The landslide situations occur in cases of heavy precipitations which accumulate not only in few hours, but frequently in a few days. Because of this aspect, it is important to study the precipitation behavior in a few days prior to the events. Figure 9 shows the mean precipitation anomaly accumulated during the three days before the selected dates (DAY-3 to DAY-1). In the SACZ cases (Fig.9a), it is worth noticing that the precipitation of previous days is concentrated to the south of the relevant region, but still affecting the Serra do Mar, with maximum values inland and over the southern coast of the state of Sao Paulo. This pattern suggests that precipitation is located to the south of the normal SACZ position and moves toward the north on DAY-0 due to the shortwave perturbation at upper levels. The precipitation anomalies related to frontal situations (Fig. 9b) appear as a narrow band centered to the south of Sao Paulo. In both cases, one can note the positive precipitation anomaly in the Serra do Mar region, which indicates that the studied episodes are not related to heavy rainfall in very short periods. Actually, a more detailed analysis reveals that the landslide events were related to the SACZ, which established 3 days before the accidents, on the average.

\subsection{Distinguishable patterns}

The anomaly fields can help to distinguish between the selected episodes and the climatological circulation patterns during the rainy season. Therefore, a further study includes the comparison of the selected cases against other events of SACZ and cold fronts that did not cause landslides. This fact is important in order to identify the characteristics which are particular to the selected extreme events for forecast purposes. The climatology of SACZ was developed by Sanches (2002) who studied the main characteristics of these systems based on the period 19802000. The climatology for the frontal systems was constructed by selecting all cases identified on the coast of Sao Paulo as identified by the Climanalise Journal within the period from 1995 to 2005. 
Figure 10 depicts the difference between the SACZ events selected for this study and the mean pattern derived from the 1980-2000 SACZ climatology. Surprisingly, the differences in the fields are very similar to the corresponding anomalies (Fig.10b-d), which indicates that the landslide SACZ events exhibit different characteristics from its climatology. The selected cases are associated with a barotropic anticyclonic anomaly, similar to blocking system, over the South Atlantic Ocean and a relatively longwave pressure field in mid and high latitudes. Different from most of the SACZ, the studied cases develop to the south of its normal position, as a band of high moisture content and strong cyclonic circulation in the lower troposphere which extends from central Brazil toward the coast of Sao Paulo. At upper levels, the mass divergence over the coast of Sao Paulo is stronger than the mean value due to the presence of a short wave cyclonic anomaly. This trough not only enhances the upper level divergence and hence the upward motions, but also causes the northward displacement of the SACZ band, which then gets positioned over the Serra do Mar. It should be mentioned that there is no significant differences in the instability indices which indicates that landslides events in Sao Paulo are more related to a synoptic dynamic pattern than extreme thermodynamic instability conditions. Similarly to the Figure 8, the differences between the selected SACZ events and the SACZ climatology can be detected 3 days before by the establishment of the barotropic anticyclonic anomaly at mid and high latitudes. High moisture content and cyclonic circulation is also evident at lower levels (figures not included). This is shown in a band configuration which extends from the central part of Brazil toward the coast of Sao Paulo.

The difference between the cold front that causes landslides and the climatological fronts of the period 1995-2005 can be noticed in Figure 11. In frontal case, the differences are larger than the anomalies, suggesting that the cold fronts are a stronger forcing on the mean circulation than the SACZ during rainy season. In general, the cold fronts that are associated with landslides in the Serra do Mar are stronger than the average, as Figure 11 shows. In particular, the surface trough is deeper and followed by a transient anticyclone stronger and colder than the average. Wind differences at $850 \mathrm{hPa}$ show significant cyclonic circulation and specific humidity vales of about $1-1.5 \mathrm{~g} / \mathrm{kg}$ higher than the climatology. It can be noticed that the humidity maximum is located over the target region. 
Nevertheless, the Lifted Index is only $1{ }^{\circ} \mathrm{C}$ colder (more unstable) than the mean. The $500-\mathrm{hPa}$ trough is stronger and intensifies the upper level jet directly over the coast of Sao Paulo.

In summary, the special cold fronts of this study were more intense from the dynamical and thermodynamic point of view in comparison with the climatology taken from 1995-2005. These characteristics can be identified by the surface, 850 and $250-\mathrm{hPa}$ fields, in general, about 48 hours before its passage by the Serra do Mar region.

\section{CONCLUSIONS}

The present work is an attempt to improve the forecast of meteorological conditions which cause landslides in the Serra do Mar. The paper focused on the study of the synoptic patterns associated with the rain induced landslide events that caused deaths during the rainy season from 1995 to 2005 period. The dates of these events were provided by Technology Research Institute of Sao Paulo and the corresponding patterns were derived from composites of the cases taken from NCEP Reanalyses.

More than $80 \%$ of the cases are related to synoptic or larger scale systems. The South Atlantic Convergence Zone and the cold front passages are the major rain producing systems which caused landslides in Serra do Mar. A detailed study of each event reveals that in about $50 \%$ of the SACZ cases the precipitation band was located over Sao Paulo for more than 2 days.

The cases of SACZ that caused deaths by landslides occur within a pattern of longwaves in high latitudes, with a ridge over the Southern Atlantic Ocean and a trough over the Pacific Ocean near the western coast of South America. The high pressure over the Atlantic Ocean has features typical of blocking conditions (warm center and upright axis) and appears as a semi-permanent Atlantic anticyclone stretching toward south. This condition combined with cyclonic circulation at upper levels in subtropical latitudes modifies the position of SACZ by displacing it to the south of its climatological position. This pattern has higher moisture content at lower levels and a larger upper-level divergence as compared to climatological situation. In the 24 hours prior to the landslide occurrences, the shortwave upper level trough interacts with the SACZ by intensifying it and 
displacing toward the north near the coast of Sao Paulo. The intensity and position of the maximum mass divergence at $250 \mathrm{hPa}$, combined with the aforementioned conditions, seems to be a good guidance for forecasting this type of phenomenon. The cold fronts that cause deaths by landslides are more intense than average. The lower level mean fields exhibit the trough followed by more intense ridge and associated with strong meridional temperature gradient. The thermodynamic instability is slightly stronger than the climatology of these systems and is combined with stronger cyclonic circulation in the mid and upper troposphere. In the frontal case, the timing of landslides coincides with the positioning of the 250hPa trough over Serra do Mar region.

In general, the synoptic patterns associated with the studied events can be identified 72 and 48 hours before the events, in both SACZ and frontal cases.

The present work was carried out by considering the dates when deaths due to landslides were registered in the Serra do Mar region. However, landslides that may have occurred in inhabited places were not included in this methodology.

\section{Acknowledgments}

The authors would like to thank MSc Marcos Barbosa Sanches for the discussion on various aspects related to the SACZ activity in the Southeastern part of Brazil. The help from MSc Helio Camargo in retrieving the NCEP reanalyses is here acknowledged. This work is partially funded by the Sao Paulo Science Support Foundation (FAPESP) under the grant no. 04/09469-0 and partially by Brazilian Research Concil (CNPq) under grant no. 308725/2007-7.

\section{Reference}

Dallavalle J.P.,Bosart L.F.(1975) A synoptic investigation of anticyclogenesis accompanying North American polar air outbreaks. Mon. Wea. Rev., 103, 11, 941-957.

Ducrocq, V., Ricard, D., Lafore, J. P., Orain, F. (2002) Storm-scale numerical rainfall prediction for five precipitating events over France: On the importance of initial humidity field. Wea. and Forecasting, 17, 1236-1256.

Durran D., (1990): Mountain waves and downslope winds: Atmospheric Processes over complex Terrain. William Blumen, Ed, Meteor. Monogr., 23, No. 45, 59-81.

Gallus, Jr, W. A. (1999) Eta simulations of three extreme precipitation events: sensitivity to resolution and convective parameterization. Weather and Forecasting, 14, 405-426.

Haas R. (2002); Simulações da Chuva Orográfica Associada a um Ciclone Extratropical no Litoral Sul do Brasil, DSc thesis. Universidade de São Paulo, Sao Paulo, Brasil. 
Kalnay E and co-authors (1996) The NCEP/NCAR 40-Year Reanalysis Project. Bull Amer Meteor Soc 77: 437-471.

Kousky, V.E.; Gan, M.A. (1981). Upper tropospheric cyclonic vortices in the tropical South Atlantic. Tellus, 36(6):538-551

Lenters, JD, Cook, K (1997) "On the origin of the Bolivian high and related circulation features of the South America climate" J Atmos Sci 54: 656-677

Mendes, L.L. (2006) Simulação numérica de evento extremo de chuva: Um estudo de caso em Angra dos Reis, RJ. MSc Dissertation Instituto Nacional de Pesquisas Espaciais. São José dos Campos, Brasil.

Revista Climanálise, Edited by Centro de Previsão de Tempo e Estudos Climáticos. Instituto Nacional de Pesquisas Espaciais (INPE), Brazil, year 1995 to 2005. Available at: http://www.cptec.inpe.br/products/climanalise/

Romero, R. et al. (1995) The influence of vegetation on the Development and structure of mountain waves. Journal of Applied Meteorology, v. 34, p. 2230-2242.

Romero, R; Doswell III, C. A.; Ramis, C. (2000) Mesoscale numerical study of two cases of longlived quasi-stationary convective systems over eastern Spain. Mon. Wea. Rev., 128, 3731-3751.

Rozante, J. R., (2001) Aninhamento do Modelo Regional Eta sobre América do Sul .MSc Dissertation Instituto Nacional de Pesquisas Espaciais. São José dos Campos, Brasil.

Sanches M.B. (2002) Análise sinótica da Zona de Convergência do Atlântico Sul (ZCAS) utilizando-se a técnica de composição. MSc Dissertation. Instituto Nacional de Pesquisas Espaciais. São José dos Campos, Brasil.

Satyamurty P.,Santos, R.P.; Lemes M.A.M., (1980) On the stationary trough generated by the Andes. Mon. Wea Rev., 108, 510-519.

Satyamurty P., Gonçalves G., Mattos L.F., Calbete N.O., Machado L.H.R. (2002) Campos diagnósticos associados ao episódio de chuvas fortes na Região de da Serra de Mantiqueira do começo do ano 2000. XII Congresso Brasileiro de Meteorologia, Foz de Iguaçu.

Seluchi M.E., Marengo, J.A (2000): Tropical_midlatitude Exchange of Air Masses During Summer and Winter in South America: Climatic Aspects and Examples of Intense Events. Int. Jou. Climat, 20, 1167-1190.

Vera C, Higgins W, Amador J, Ambrizzi T, Garreaud R, Gochis D, Gutzler D, Lettenmaier D, Marengo J,Mechoso CR (2006) Toward a Unified View of the American Monsoon Systems. Journal of Climate 19(20): 4977 
Figure Legend

Figure 1: Topography (meters) and location of the Serra do Mar and the state of Sao Paulo in Brazil.

Figure 2 - Composite of (a) mean sea level pressure (hPa, solid line) and 500/1000-hPa layer thickness ( $\mathrm{m}$, dashed line); (b) $850-\mathrm{hPa}$ specific humidity ( $\mathrm{g} / \mathrm{kg}$, solid line) and winds (full barb is equal to $10 \mathrm{~m} / \mathrm{s}$ ); and (c) $250-\mathrm{hPa}$ mass divergence $\left(\times 10^{-5} \mathrm{~s}^{-1}\right.$, solid line) and winds (full barb is equal to $10 \mathrm{~m} / \mathrm{s})$.

Figure 3 - Anomaly with respect to NCEP reanalysis climatology from 1950-1998 of mean sea level pressure (hPa, shaded) and 500/1000-hPa layer thickness (m, solid line) for (a) SACZ case and (b) frontal case.

Figure 4 - Anomaly with respect to NCEP reanalysis climatology from 1950-1998 of 850-hPa specific humidity ( $\mathrm{g} / \mathrm{kg}$, shaded) and winds ( $\mathrm{m}$, full barb is equal to $10 \mathrm{~m} / \mathrm{s}$ ) for (a) SACZ case and (b) frontal case.

Figure 5 - Anomaly with respect to NCEP reanalysis climatology from 1950-1998 of 500-hPa geopotential height ( $\mathrm{m}$, shaded) and temperature (K, solid line) for (a) SACZ case and (b) frontal case.

Figure 6 - Anomaly with respect to NCEP reanalysis climatology from 1950-1998 of 250-hPa mass divergence $\left(\times 10^{-5} \mathrm{~s}^{-1}\right.$, shaded) and winds ( $\mathrm{m}$, full barb is equal to $10 \mathrm{~m} / \mathrm{s}$ ) for (a) SACZ case and (b) frontal case.

Figure 7 - Anomaly of mean sea level pressure (hPa, shaded) and 500/1000-hPa layer thickness (m, solid line) taken on 3, 2 and 1 day before the SACZ events (upper row) and (b) frontal events (lower row).

Figure 8 - Anomaly of 250-hPa mass divergence (x10-5 $\mathrm{s}^{-1}$, shaded) and winds ( $\mathrm{m}$, full barb is equal to $10 \mathrm{~m} / \mathrm{s}$ ) taken on 3,2 and 1 days before the SACZ events (upper row) and (b) frontal events (lower row).

Figure 9 - Anomaly of precipitation (mm) taken 3 days before the SACZ (a) and cold front (b) events.

Figure 10 - Differences between landslide SACZ and climatology SACZ of (a) mean sea level pressure (hPa, shaded) and 500/1000-hPa layer thickness (m, solid line); (b) 850-hPa specific humidity $(\mathrm{g} / \mathrm{kg}$, shaded) and winds (m/s, full barb is equal to $10 \mathrm{~m} / \mathrm{s})$; (c) $500-\mathrm{hPa}$ geopotential height ( $\mathrm{m}$, shaded) and temperature (K, solid line); and (d) 250-hPa mass divergence ( $\times 10^{-5} \mathrm{~s}^{-1}$, shaded) and winds ( $\mathrm{m}$, full barb is equal to $10 \mathrm{~m} / \mathrm{s}$ ).

Figure 11 - Differences between landslide cold fronts and climatology cold fronts of (a) mean sea level pressure (hPa, shaded) and 500/1000-hPa layer thickness (m, solid line); (b) 850-hPa specific humidity ( $\mathrm{g} / \mathrm{kg}$, shaded) and winds ( $\mathrm{m}$, full barb is equal to $10 \mathrm{~m} / \mathrm{s}$ ); (c) $500-\mathrm{hPa}$ geopotential 
height ( $\mathrm{m}$, shaded) and temperature (K, solid line); and (d) 250-hPa mass divergence ( $\times 10^{-5} \mathrm{~s}^{-1}$, shaded) and winds ( $\mathrm{m} / \mathrm{s}$, full barb is equal to $10 \mathrm{~m} / \mathrm{s})$.

Table 1 - Monthly total number of precipitation induced landslide events in Serra do Mar between 1995 and 2005.

\begin{tabular}{|c|c|}
\hline Month & N. of events \\
\hline January & 13 \\
\hline February & 7 \\
\hline March & 6 \\
\hline April & 4 \\
\hline November & 2 \\
\hline December & 1 \\
\hline TOTAL & $\mathbf{3 3}$ \\
\hline
\end{tabular}




\section{Figures}

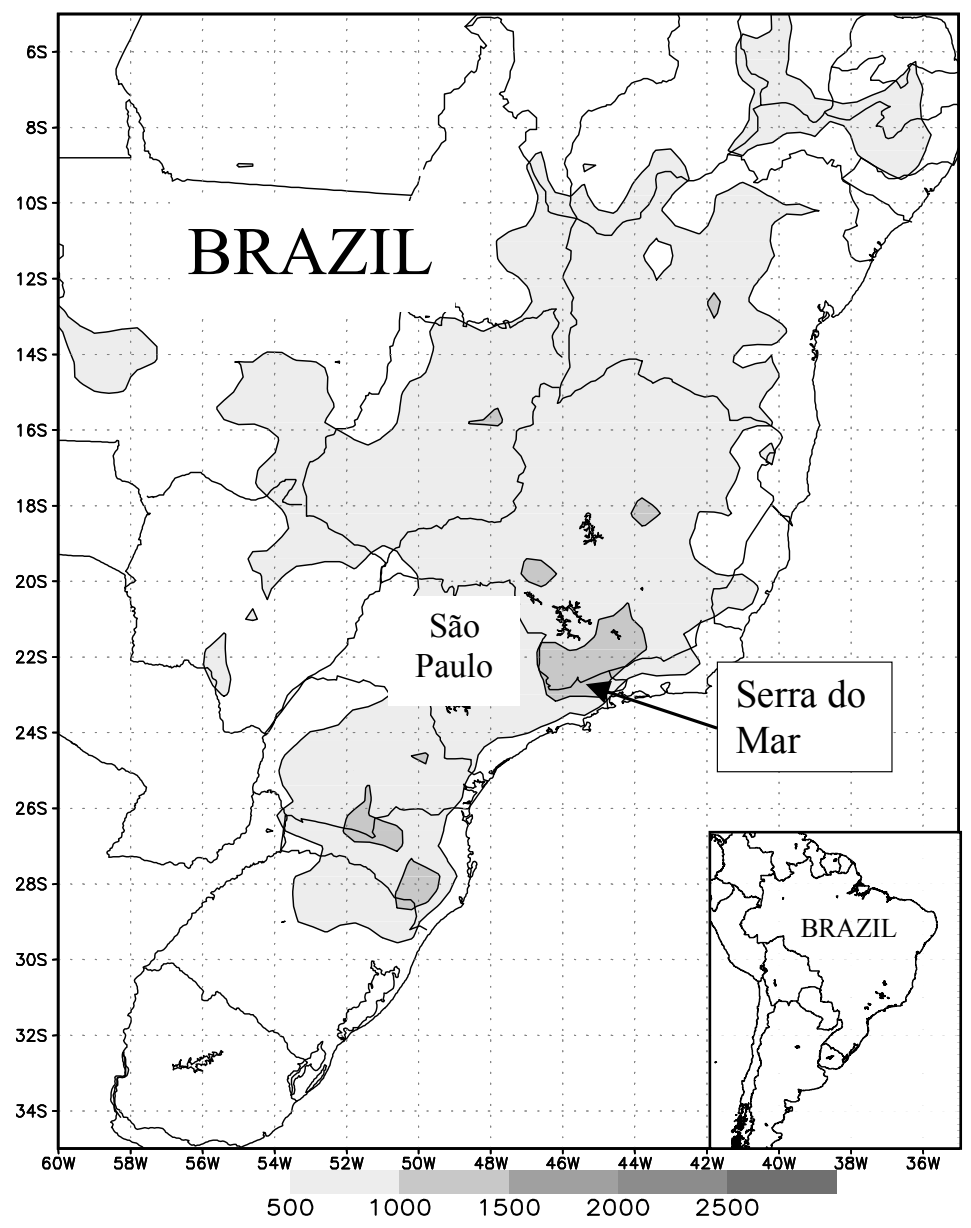

Figure 1: Topography (meters) and location of the Serra do Mar and the state of Sao Paulo in Brazil. 


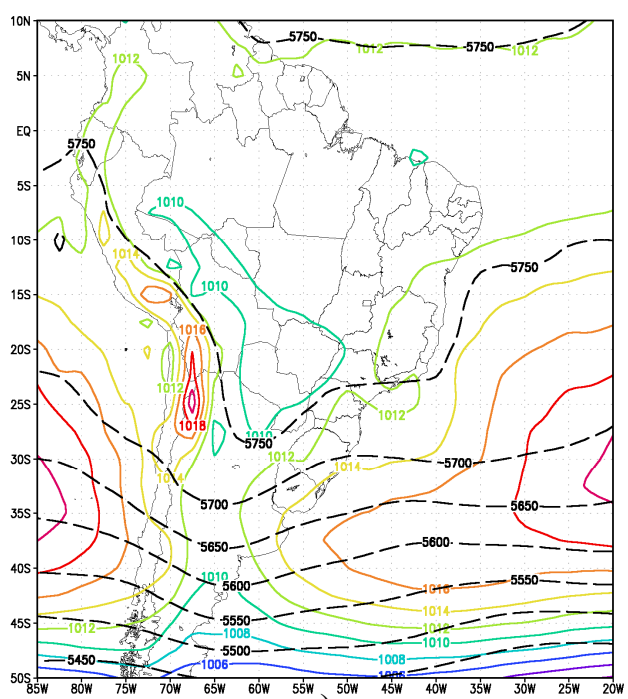

a)

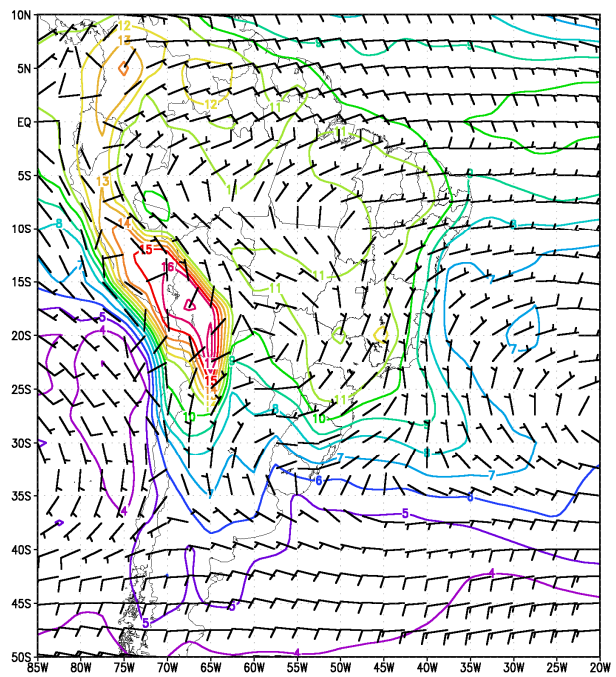

b)

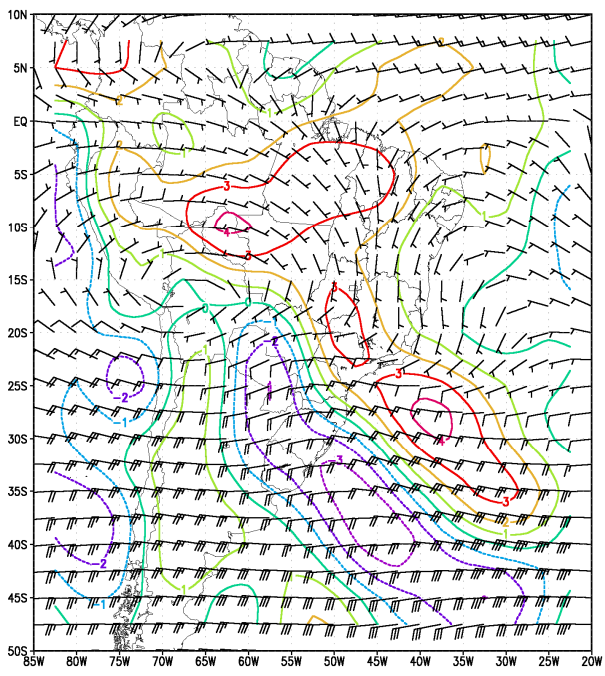

c)

Figure 2 - Composite of (a) mean sea level pressure (hPa, solid line) and 5001000-hPa layer thickness (m, dashed line); (b) 850-hPa specific humidity (g/kg, solid line) and winds (full barb is equal to $10 \mathrm{~m} / \mathrm{s}$ ); and (c) $250-\mathrm{hPa}$ mass divergence $\left(\times 10^{-5} \mathrm{~s}^{-1}\right.$, solid line) and winds (full barb is equal to $10 \mathrm{~m} / \mathrm{s}$ ). 


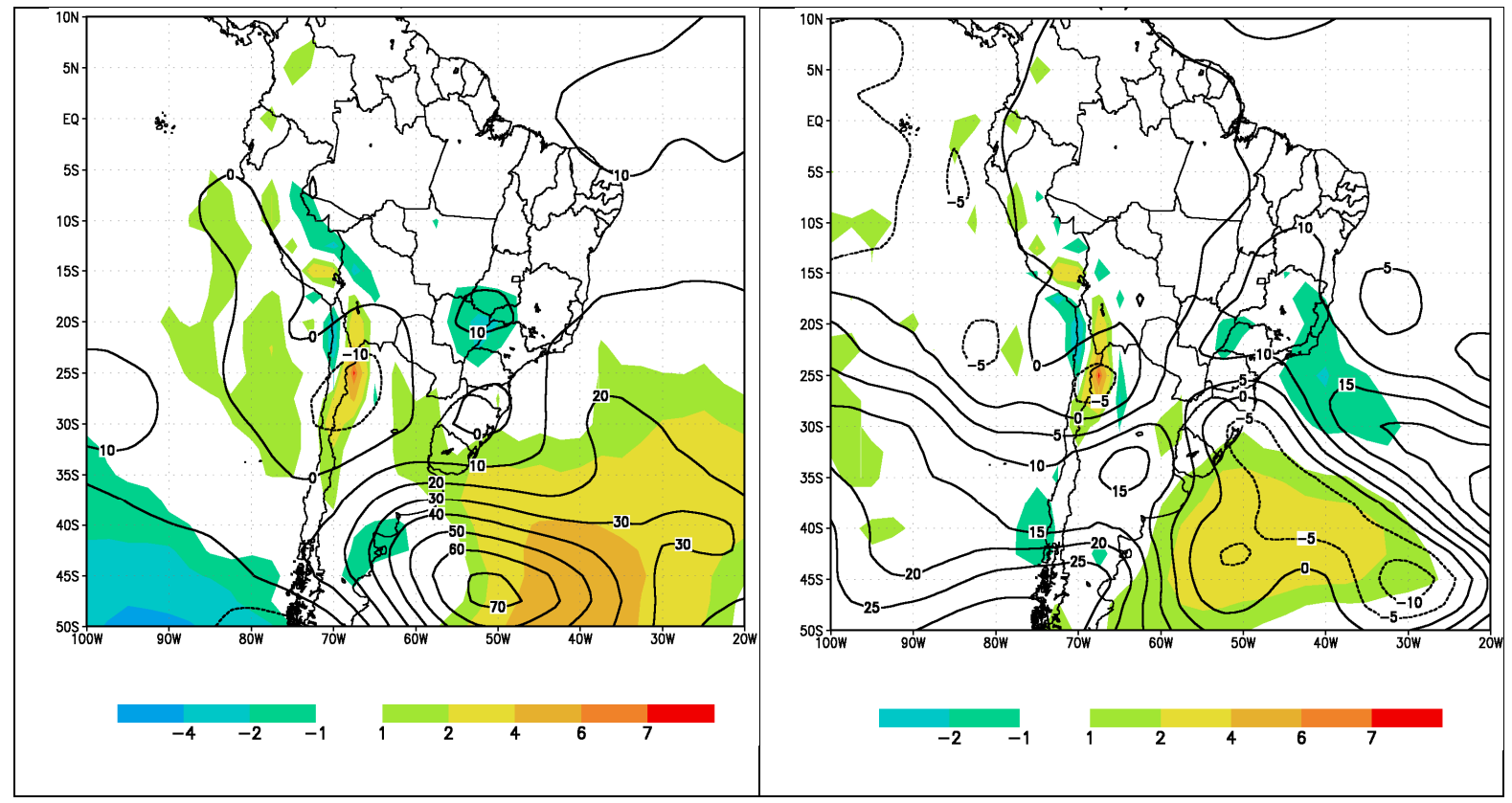

Figure 3 - Anomaly with respect to NCEP re-analyses climatology from 19501998 of mean sea level pressure (hPa, shaded) and 500/1000-hPa layer thickness (m, solid line) for (a) SACZ case and (b) frontal case. 


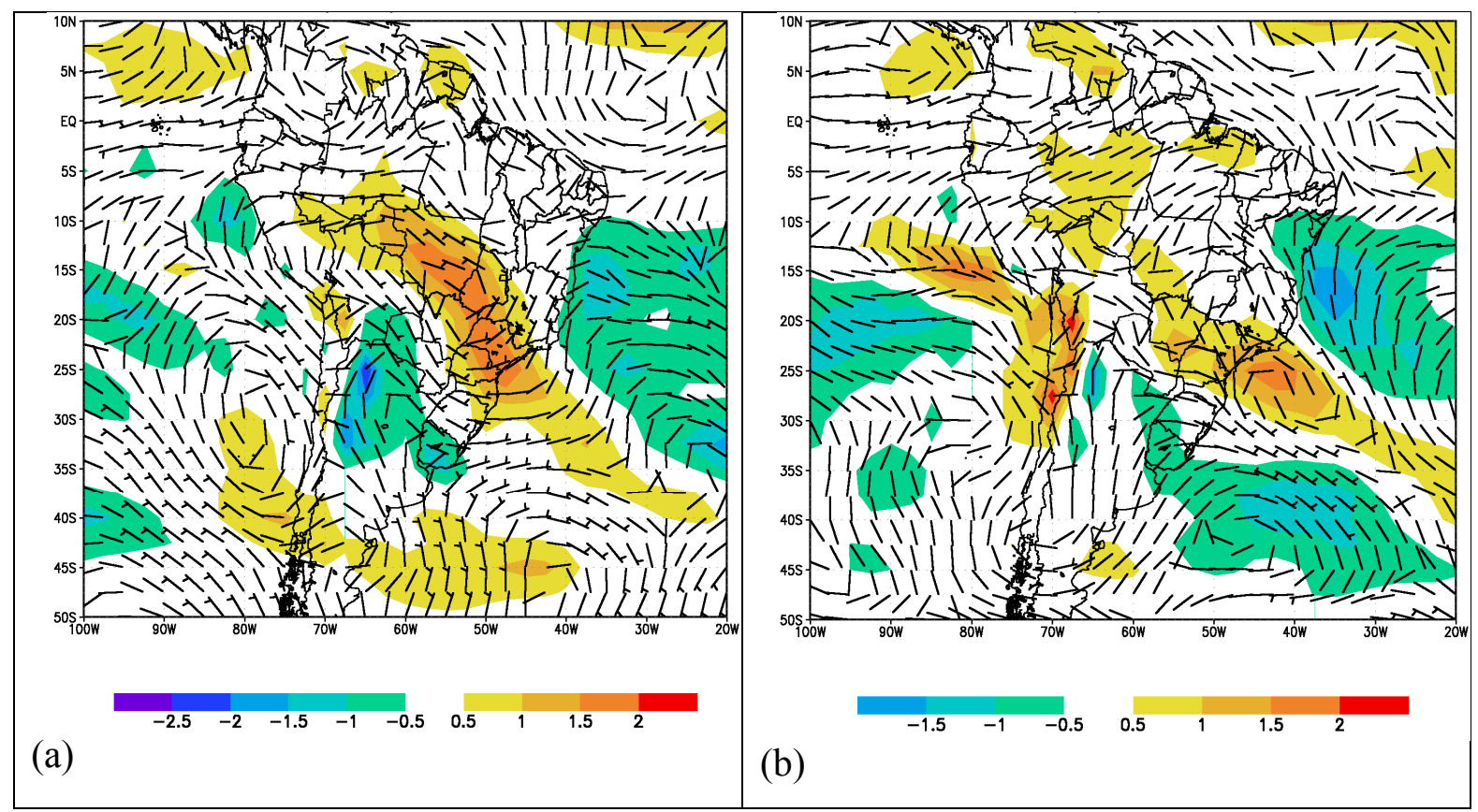

Figure 4 - Anomaly with respect to NCEP reanalyses climatology from 19501998 of 850 -hPa specific humidity ( $\mathrm{g} / \mathrm{kg}$, shaded) and winds ( $\mathrm{m}$, full barb is equal to $10 \mathrm{~m} / \mathrm{s}$ ) for (a) SACZ case and (b) frontal case.

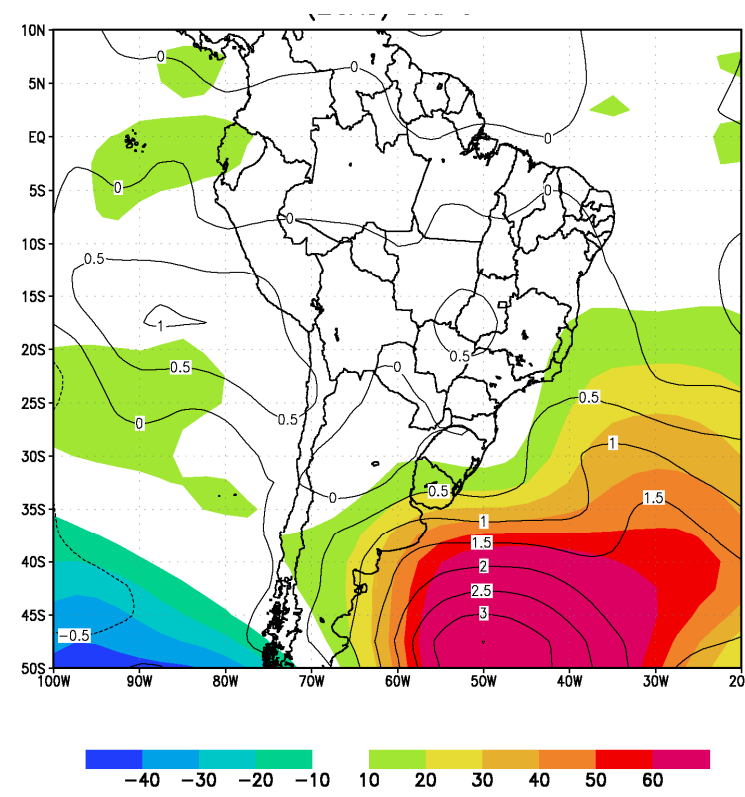

(a)

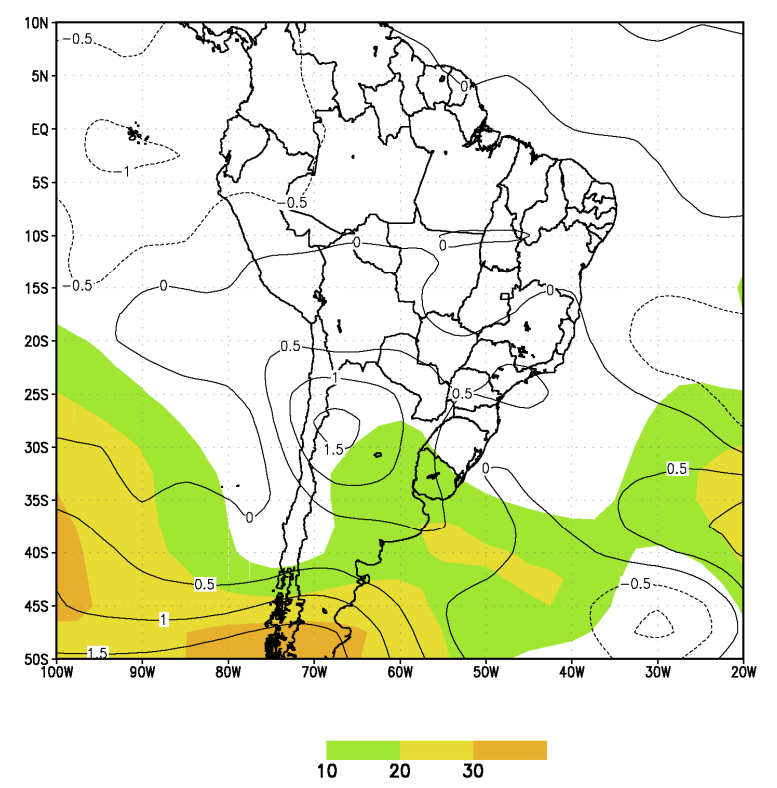

(b)

Figure 5 - Anomaly with respect to NCEP reanalyses climatology from 19501998 of 500-hPa geopotential height (m, shaded) and temperature (K, solid line) for (a) SACZ case and (b) frontal case. 

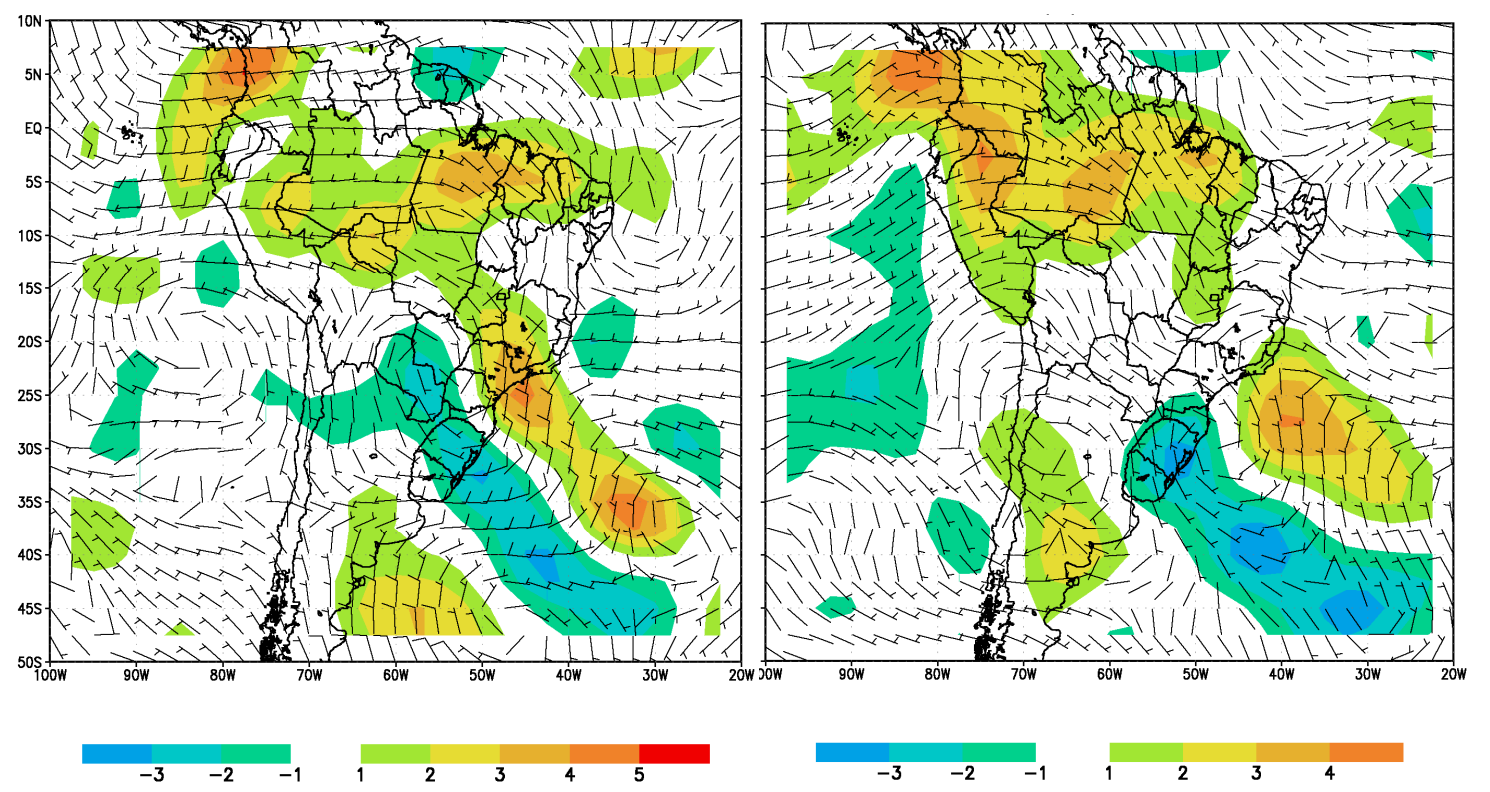

Figure 6 - Anomaly with respect to NCEP reanalyses climatology from 19501998 of $250-\mathrm{hPa}$ mass divergence $\left(\times 10^{-5} \mathrm{~s}^{-1}\right.$, shaded) and winds $(\mathrm{m} / \mathrm{s}$, full barb is equal to $10 \mathrm{~m} / \mathrm{s}$ ) for (a) SACZ case and (b) frontal case.
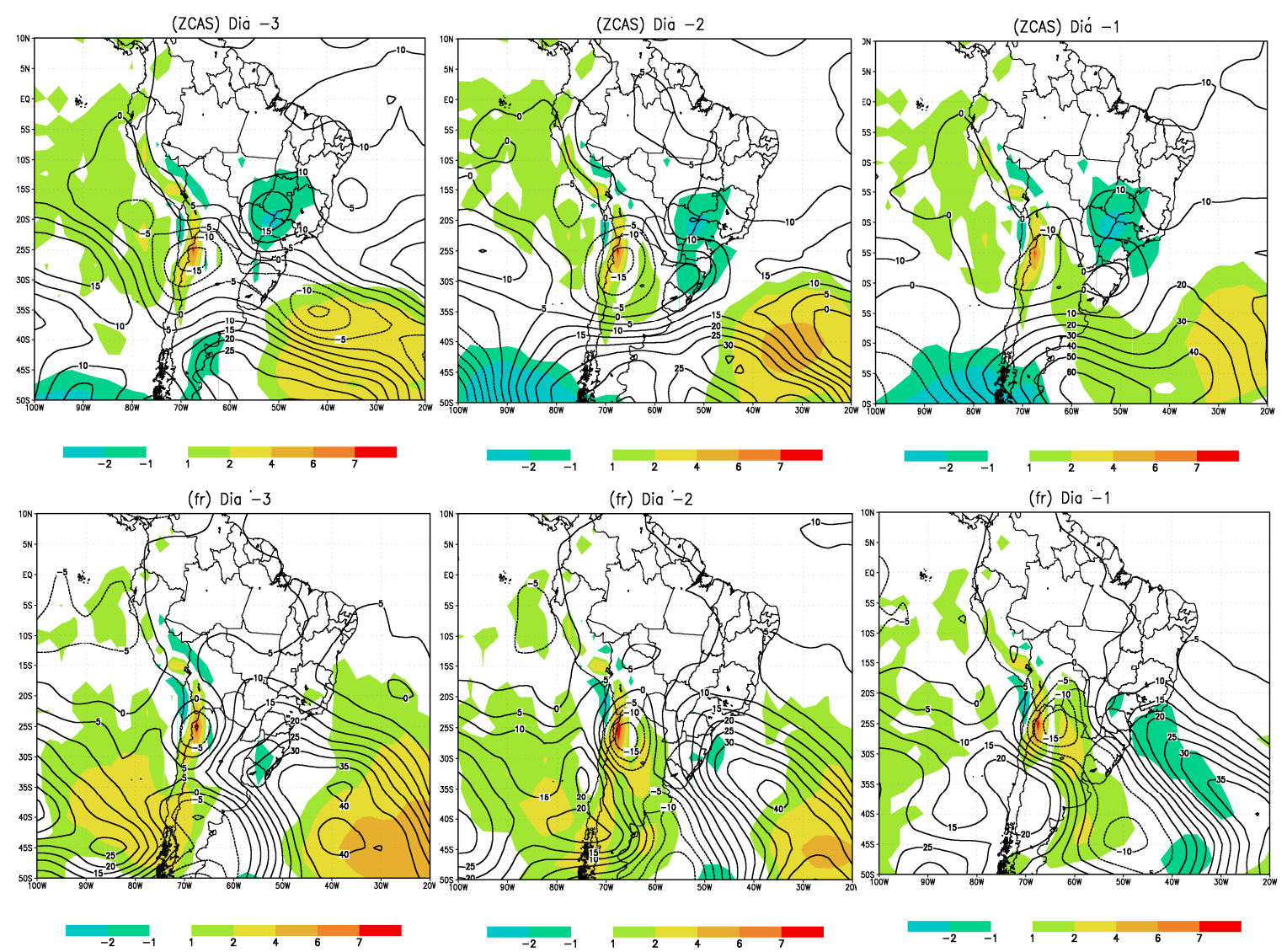

Figure 7 - Anomaly of mean sea level pressure (hPa, shaded) and 500/1000-hPa layer thickness ( $\mathrm{m}$, solid line) taken on 3,2 and 1 day before the SACZ events (upper row) and (b) frontal events (lower row). 

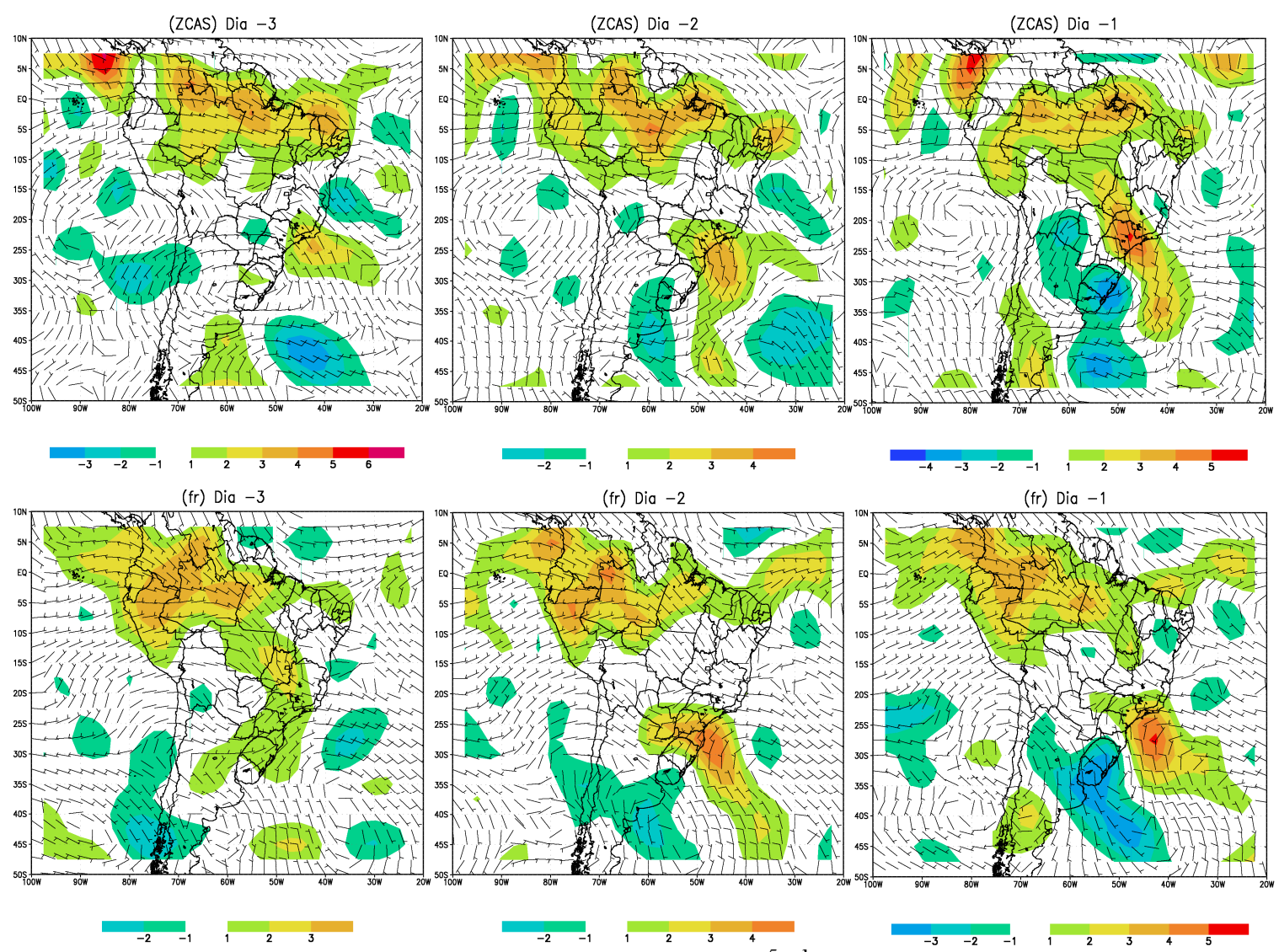

Figure 8 - Anomaly of 250-hPa mass divergence $\left(\times 10^{-5} \mathrm{~s}^{-1}\right.$, shaded) and winds ( $\mathrm{m}$, full barb is equal to $10 \mathrm{~m} / \mathrm{s}$ ) taken on 3,2 and 1 days before the SACZ events (upper row) and (b) frontal events (lower row)
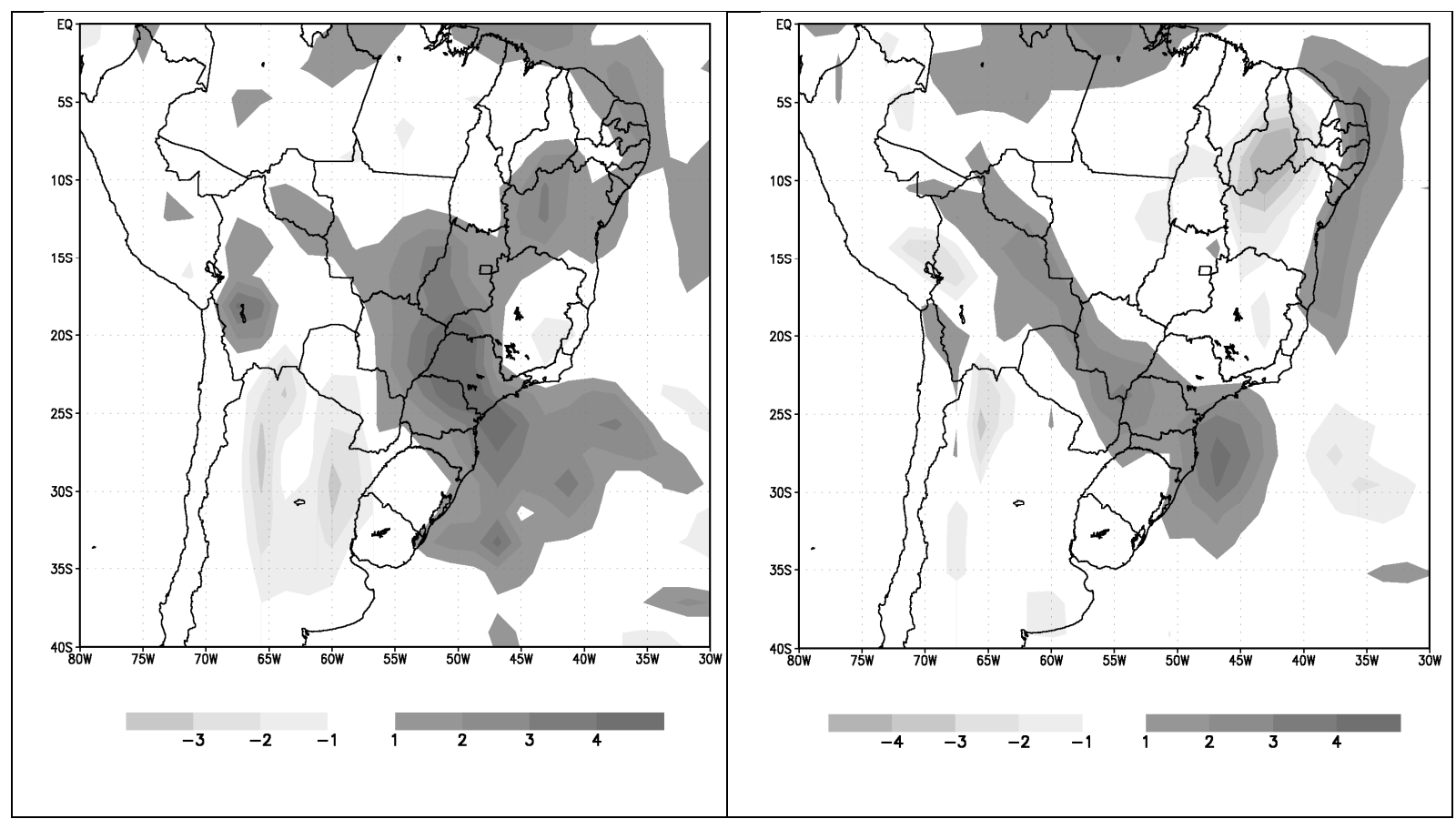

Figure 9 - Anomaly of accumulated precipitation $(\mathrm{mm})$ taken during the 3 days before the SACZ (a) and cold front (b) events. 


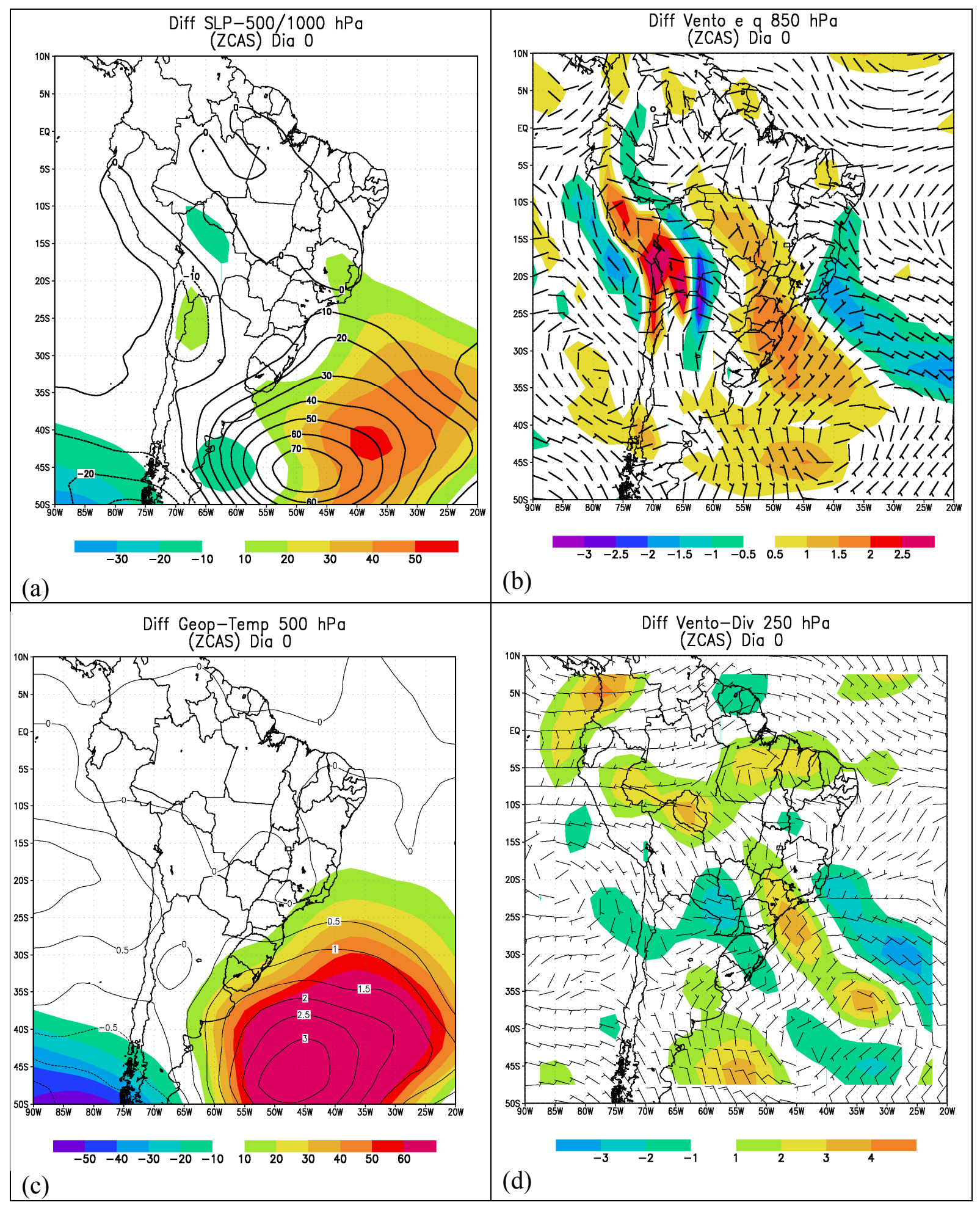

Figure 10 - Differences between landslide SACZ and climatology SACZ of (a) mean sea level pressure (hPa, shaded) and 500/1000-hPa layer thickness (m, solid line); (b) 850-hPa specific humidity ( $\mathrm{g} / \mathrm{kg}$, shaded) and winds ( $\mathrm{m}$, full barb is equal to $10 \mathrm{~m} / \mathrm{s})$; (c) $500-\mathrm{hPa}$ geopotential height (m, shaded) and temperature (K, solid line); and (d) $250-\mathrm{hPa}$ mass divergence $\left(\mathrm{x}^{-5} 0^{-5} \mathrm{~s}^{-1}\right.$, shaded) and winds (m, full barb is equal to $10 \mathrm{~m} / \mathrm{s})$. 


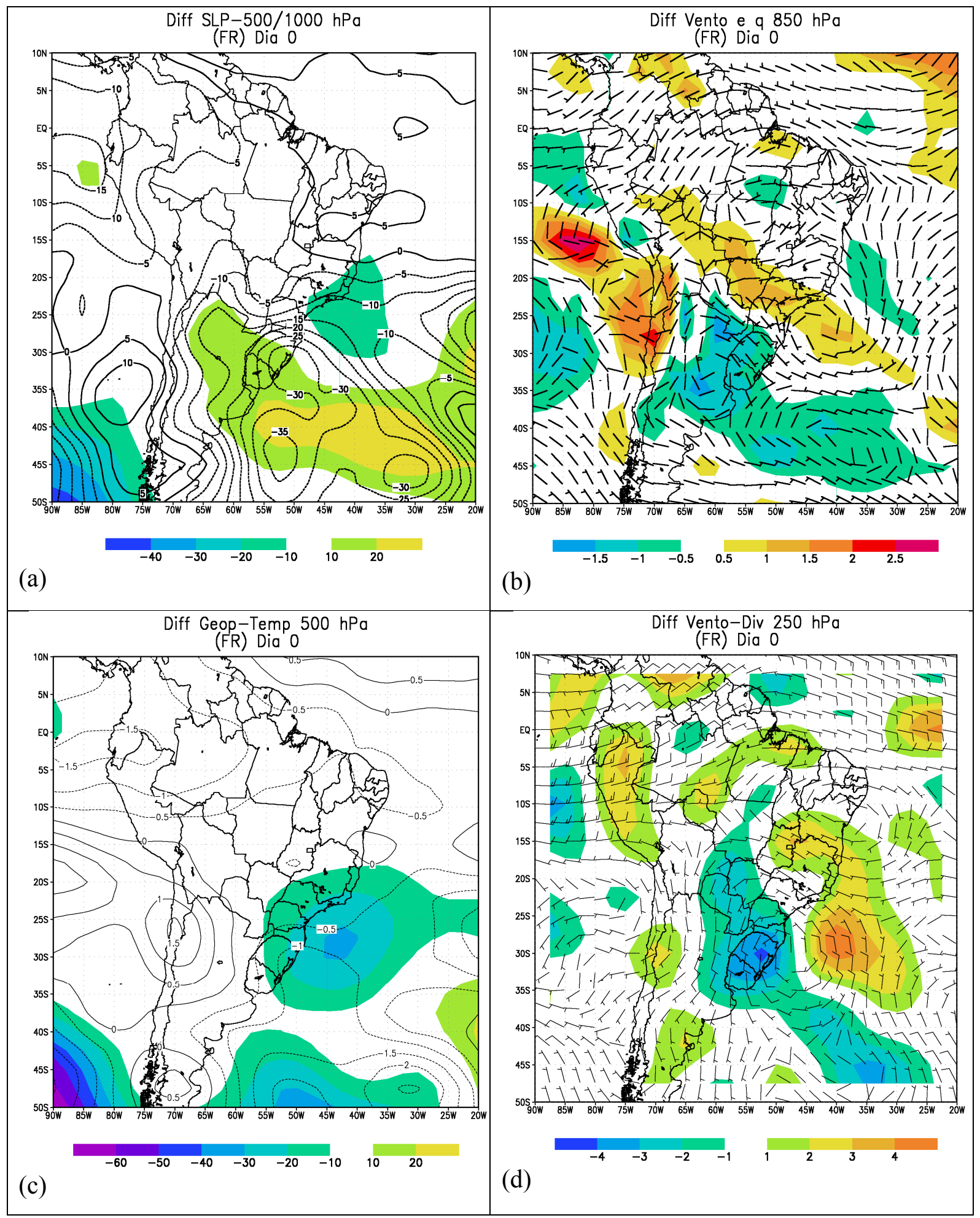

Figure 11 - Differences between landslide cold fronts and climatology cold fronts of (a) mean sea level pressure (hPa, shaded) and 500/1000-hPa layer thickness (m, solid line); (b) 850-hPa specific humidity ( $\mathrm{g} / \mathrm{kg}$, shaded) and winds ( $\mathrm{m}$, full barb is equal to $10 \mathrm{~m} / \mathrm{s})$; (c) $500-\mathrm{hPa}$ geopotential height ( $\mathrm{m}$, shaded) and temperature (K, solid line); and (d) $250-\mathrm{hPa}$ mass divergence ( $\mathrm{x} 10^{-5} \mathrm{~s}^{-1}$, shaded) and winds (m, full barb is equal to $10 \mathrm{~m} / \mathrm{s}$ ). 